\title{
ERKEK HASTALARIN PROSTAT KANSERİ TARAMALARI HAKKINDA BİLGİ DÜZEYLERİ
}

\author{
Knowledge Levels of Male Patients About Prostate Cancer Screening
}

\section{Özlem CEYHAN ${ }^{1}$, Songül GÖRİş ${ }^{1}$, Abdullah DEMIRTAŞ ${ }^{2}$, Züleyha KILIÇ¹}

\author{
${ }^{l}$ Erciyes Üniversitesi Sağllk Bilimleri Fakültesi, Hemşirelik A.D., KAYSERİ, TÜRKIYE \\ ${ }^{2}$ Erciyes Üniversitesi Tip Fakültesi, Üroloji A.D., KAYSERI, TÜRKIYYE
}

Amaç: Prostat kanseri erkeklerde en s1k görülen kanserlerdendir. İleri evre olmadan belirti vermeyen prostat kanserinde, erken tanı ve taramalarla iyi sonuçlar elde edilebilir. Bu çalışma erkeklerin prostat kanseri taramalarına ilişkin bilgi düzeylerini tespit etmek amacıyla yapılmıştır.

Gereç ve Yöntem: Araştırma bir üniversite hastanesinin üroloji polikliniğine başvuran 120 erkek hasta ile yapılmıştır. Araştırmanın yapılabilmesi için etik kurul onayı, kurum izni ve bireylerden sözlü ve yazılı onam alınmıştır. Araştırmanın verileri; literatür taranarak oluşturulan Kișisel Bilgi Formu ve Weinrich ve arkadaşları tarafından geliştirilen "Prostat Kanseri Taramaları Bilgi Testi"(PKTBT) kullanılarak toplanmıştır.

Bulgular: Araştırmada bireylerin yaş ortalaması $63.26 \pm 2.24$, $\% 91.7$ 'si evli, \%58.3'ü ilköğretim mezunu ve \%70.8'i emekliydi. Bireylerin daha önce \%38.3'ünün prostat ile ilgili sorun yaşadığ,$\% 39.2$ 'sinin prostat muayenesi olduğu, \%30'nun PSA testi yaptırdığı ve \%28.3'ünün yakınlarında prostat kanseri olduğu belirlenmiştir. Bireylerin sadece $\% 21.7$ 'sinin prostat kanseri hakkında bilgi aldığ alanların \%30.8'inin bilgiyi sağlı personelinden aldığı tespit edilmiștir. Araștırmaya katılan bireylerin "Prostat Kanseri Taramaları Bilgi Testinden" ortalama $4.81 \pm 2.24$ puan aldığ ve "düşük düzeyde bilgili" oldukları saptanmıștır. Prostat kanseri taramaları konusunda daha önce bilgi alan erkeklerin PKTBT puanlarının daha yüksek olduğu belirlenmiştir. Daha önce prostat kanserine yönelik bilgi alan erkekler ile almayanların PKTBT puanları arasındaki farkın istatistiksel olarak ileri derecede anlamlı olduğu tespit edilmiştir.

Sonuç: $\mathrm{Bu}$ araştırmanın sonucunda riskli grupta yer alan erkeklerin prostat kanseri ve taramalara ilişkin bilgi düzeylerinin düşük olduğu saptanmıștır. Bu konuda halka yönelik kamu spotu çalışmalarıyla erkeklerin dikkatinin çekilmesi ve bilgilendirmelerinin yapılması önerilmektedir.

Anahtar Kelimeler: Bilgi düzeyi; prostat kanseri, prostat kanser taramalarl
Objective: Prostate cancer is the most common cancer in men. Prostate cancer that does not show symptoms without advanced stage is a type of cancer that shows good results with early diagnosis and screening. This study was done descriptively to determine the level of knowledge about men's screening for prostate cancer.

Material and Methods: The study was conducted with 120 male patients who applied to the urology policlinic of a university hospital. Ethical committee approval, institutional permission and verbal and written consent from the individuals were obtained. Data from the study were retrieved by the Personal Information Form created by searching the literature and "Prostate Cancer Screening Information Test" (PCTBT) developed by Weinrich et al.

Results: In the study, it was determined that the average age of the individuals was $63.26 \pm 2.24,91.7 \%$ were married, $58.3 \%$ were primary school graduates and $70.8 \%$ were retired. It was determined that $38.3 \%$ of the individuals had problems with prostate, 39.2\% had prostate underwent, 30\% had PSA test and $28.3 \%$ had prostate cancer in their relatives. It was determined that only $21.7 \%$ of the individuals received information about prostate cancer and $30.8 \%$ of the individuals received information from health care personnel. Individuals participating in the study had an average of $4.81 \pm 2.24$ points from the "Prostate Cancer Screening Tests" and were found to be "low-level knowledgeable". Men with previous knowledge of prostate cancer screenings were found to have higher PCTBT scores. It was determined that the difference between PCTBT scores of males who were previously informed about prostate cancer was statistically significant.

Conclusion: As a result of this research, it was determined that men in risk group had low knowledge level about prostate cancer and screening. In this regard, it is suggested that the public awareness of the men should be inreased with the public spot work towards the public.

Keywords: Knowledge level; prostate cancer, prostate cancer screenings 


\section{GíRiş}

Tanı ve tedavi yöntemlerindeki yenilikler, insanların bilinçlenmesi, sağlık kuruluşlarından yararlanma oranının artması, birçok akut ve kronik hastalığın tanı ve tedavisindeki gelişmeler, bunlara bağlı olarak ortalama yaşam süresinin uzaması ve başka birçok nedenle kanser; günümüzde önemli evrensel sağlık sorunlarından biri haline gelmiştir $(1,2)$. Kanser hem dünyada hem de ülkemizde \%22'lik görülme sıklığı ile kardiyovasküler hastalıklardan sonra ikinci ölüm nedeni olarak karşımıza çıkmaktadır (3). 2012 yılında 14.1 milyon yeni kanser vakasının ortaya çıktığı, 8.2 milyon kişinin kanser nedeniyle hayatını kaybettiği, 32.6 milyon kişinin kanserle birlikte yaşadığ edilmiştir (4).

Kanser görülme sıklığı cinsiyete göre farklılık göstermektedir. Kanser erkeklerde kadınlara oranla \%25 daha fazla görülmektedir (4). Erkeklerde en s1k görülen kanserler arasında, prostat kanseri ikinci sıradadır $(5,6)$. Bir erkekte 0-39 yaş arasında prostat kanserine yakalanma olasılığı \%0.01 iken, 40-59 yaş $\operatorname{aras1} \% 2.58,60-79$ yaş arası ise \%14.7 ve yaşam boyu prostat kanseri gelişme olasılığ $1 \% 17.8$ 'dir (7).

Birçok kanser türünde olduğu gibi, prostat kanserinin de kendine özgü erken belirtileri yoktur. Ancak ileri evre belirtileri ortaya çıkınca kişiler sağlık kuruluşuna başvurmaktadır. İleri evrelerde tanı konmuş prostat kanseri tedavi şansı olmaksızın ölüme yol açabilmektedir (8). Kanser vakalarında taramalarla ve erken tedavi ile yaşama şansının arttığı göz önüne alınacak olursa birincil ve ikincil korunmanın önemi daha iyi anlaşılmaktadır (1-3, 9-15). Prostat kanseri taramalarında erkeklerin taramalara katılmalarını etkileyen birçok faktör bulunmaktadır. Yapılan araştırmalarda kanser olma korkusu, utanma, erkekliğe tehdit olarak algılanması gibi birçok faktörün taramalara katılımı azalttığı görülmektedir. Bunun yanı sıra taramalara yönelik bilgi eksikliği taramalara katılımı etkileyen önemli bir faktör olarak karşımıza çıkmaktadır (16-23). Wray ve ark.'nın Afrika kökenli Amerikalı bireylerle yaptıkları çalışmada; prostat kanserine yönelik bilgi eksikliğinin taramalara katılımı sağlamada bir engel olduğu saptanmıştır (18). Agho ve Lewis'in, Afrika kökenli Amerikalı bireylerin prostat kanseri ve taramalarına yönelik bilgilerini inceledikleri çalışmada; katılımcıların \%40'ından daha azının prostat kanseri hakkında yeterli bilgiye sahip olduğu, bunun yanı sıra, bilgi düzeyinin artmasıyla, taramalara katılımlarının arttığı görülmüştür (23).

Prostat kanserinde erken tanı için taramalara öncelik verilmesi ve bireylerin bu taramalara katılmalarını etkileyen faktörlerin bilinmesi kanser tedavisi için önemlidir.

$\mathrm{Bu}$ çalışma erkeklerin prostat kanseri taramalarına ilişkin bilgi düzeylerini tespit etmek amacıyla tanımlayıcı olarak yapılmıştır.

\section{GEREÇ VE YÖNTEM}

Araştırma bir üniversite hastanesinin üroloji polikliniğine herhangi bir nedenle başvuran ve prostat gelişimi yönünden riskli grupta yer alan 50 yaş üstü, iletişim kurabilen ve çalışmaya katılmayı kabul eden erkeklerle yapılmıştır. Araştırma istatistiksel gücün $\alpha=$ 0.05 güven düzeyinde $\% 80$ olarak hesaplanan 120 erkek hasta ile tamamlanmıştır.

Araştırmanın verileri; araştırmacılar tarafından literatür taranarak oluşturulan Kişisel Bilgi Formu ve Hastaların prostat kanseri taramalarına ilişkin bilgi düzeylerini değerlendirmek için "Prostat Kanseri Taramaları Bilgi Testi” kullanılarak toplanmıştır (9-11, 24-26).

\section{Kişisel Bilgi Formu}

Kişisel bilgi formu mevcut literatürden yararlanılarak hazırlanmıştır (9-11, 24-26). Kişisel bilgi formunda; yaş, eğitim durumu, medeni durum, çalışma durumu, gelir durumu, yaşadığg yer, sağlık güvencesi, önceden prostat muayenesi olma durumu ve daha önce PSA testi yaptırma durumunu, sorgulayan 15 soru yer almaktadir.

\section{Prostat Kanseri Taramaları Bilgi Testi}

Weinrich ve arkadaşları tarafından geliştirilen bilgi testinin Türkçe geçerlik ve güvenirlik çalışması Çapık ve Gözüm tarafından yapılmıştır $(25,26)$. Prostat 
kanseri taramaları bilgi testi 12 sorudan oluşmaktadır. Bilgi testi; engeller (9-12. maddeler), belirtiler (2 ve 4. madde), risk faktörleri (1 ve 3.madde), yan etkiler (6-8. maddeler) ve tarama yaşına (5. madde) yönelik maddelerden oluşmaktadır.

Maddeler; evet (doğru), hayır (yanlış) ve bilmiyorum olarak işaretlenmektedir. Her doğru yanıta "1" puan verilirken, yanlış yanıta puan verilmemektedir. Puanlama yapılırken "bilmiyorum" olarak işaretlenen maddeler yanlış cevap olarak değerlendirilmektedir (Puan verilmemektedir). Cevaplamada 8 sorunun cevab1 $(1,2,4,5,6,7,11$ ve 12) "evet" olarak işaretlenmelidir. Dört sorunun cevabı ise (3, 8, 9 ve 10) "hayır" olarak işaretlenmelidir. Bilgi testinden alınabilecek puanlar 0 ile 12 arasında değişmektedir. Puanın yükselmesi bilgi düzeyinin arttığı anlamına gelmektedir. Weinrich ve arkadaşları ayrıca; 7 ve daha az puan alan bireylerin "düşük düzeyde bilgili", 8-10 arasında puan alanların "orta düzeyde bilgili” ve 11-12 puan alanların "yüksek düzeyde bilgili" olarak da değerlendirilebileceğini belirtmektedirler (23). Bu çalışmada puan ortalamaları kullanılarak bireylerin bilgi seviyesi değerlendirilmiştir. Ölçeğin Cronbach alfa değeri bizim çalışmamızda 0.80 olarak hesaplanmıştır.

Araştırmadan elde edilen veriler bilgisayarda IBM SPSS 21.0 istatistik programında değerlendirilmiştir. Verilerin normal dağılımına Shapiro Wilks testiyle bakılmış ve gruplar arası karşılaştırmalarda, tanımlayıcı istatistikler, independent samples $\mathrm{t}$ testi, One Way Anova ve korelasyon testleri yapılmıştır. Gruplar arası farkın tespit edilmesinde ileri analizlerde Tukey testi uygulanmıştır. İstatistiksel anlamlılık $\mathrm{p}<0.05$ olarak kabul edilmiştir

Çalışmanın yapılabilmesi için; Erciyes Üniversitesi Tıp Fakültesi Dekanlığı Klinik Araştırmalar Etik Kurulu Kararı (14/685), kurum izni ve bireylerden sözlü ve yazılı bilgilendirilmiş gönüllü olur alınmıştır.

\section{BULGULAR}

Araştırmada erkeklerin yaş ortalamasının $63.26 \pm 2.24$ olduğu, \%91.7'sinin evli, \%58.3'ünün ilköğretim mezunu, \%70.8'inin emekli olduğu ve \%78.3'ünün il merkezinde yaşadığı saptanmıştır. Erkeklerin daha önce \%38.3'ünün prostat sorunu yaşadığı, \%39.2'sinin prostat muayenesi olduğu, \%30.0'ının PSA testi yaptırdığı ve \%28.3'ünün yakınlarında prostat kanseri tespit edildiği belirlenmiştir. Erkeklerin sadece \%21.7'sinin prostat kanseri hakkında bilgi aldığı, bilgi alanların \%30.8'inin bilgiyi sağlık personelinden aldığ 1 tespit edilmiştir. Ancak erkeklerin \%73.3'ünün prostat taraması (muayene ve testler) yaptırmayı düşündüğü, yaptırmak istemeyenlerinde \%62.5'inin "gerek görmediği” için yaptırmak istemediği saptanmıştır (Tablo 1).

Araştırmaya kapsamındaki erkeklerin, PKTBT'den ortalama $4.81 \pm 2.24$ puan aldığı ve "düşük düzeyde bilgili" oldukları saptanmıştır. Bireylerin yaşları ile bilgi testi puan ortalamaları arasında korelasyona bakılmış, yaş ile bilgi puan ortalamaları arasında bir ilişki bulunmamıştır ( $\mathrm{p}>0.05)$.

Araştırmada erkeklerin eğitim durumu ile bilgi testiden aldıkları puanlar değerlendirildiğinde, en yüksek bilgi seviyesine lise ve yüksekokul mezunu bireylerin sahip olduğu, gruplar arasındaki farkın anlamlı olduğu belirlenmiştir $(\mathrm{p}<0.05)$. Gruplar arası farkı belirlemek için yapılan ileri istatistiki değerlendirmede anlamlılığın ilkokul ve lise/yüksekokul mezunları arasındaki farktan kaynaklandığı saptanmıştır. Erkeklerin yaşadığı yer ile bilgi puan ortalamaları arasında anlamlılık oluşturacak bir fark saptanmamış $(\mathrm{p}>0.05)$, ancak il merkezinde yaşayanların bilgi puanları daha yüksek bulunmuştur (Tablo 2).

Erkeklerin daha önceki deneyimleri ile bilgi puan ortalamalarına bakıldığında, daha önce prostat sorunu yaşayanların, daha önce prostat muayenesi yaptıranların, yakınlarında prostat kanseri tanısı olanların bilgi puan ortalamalarının daha yüksek olduğu ve gruplar arasındaki farkın anlamlı olduğu belirlenmiştir $(p<0.05)$. Araştırmada prostat kanseri taramasını yaptırmak isteyen erkeklerin bilgi puan ortalamalarının da istemeyenlere göre daha yüksek olduğu ve gruplar arasındaki farkın anlamlılık oluşturduğu saptanmıştır $(\mathrm{p}<0.05)$ (Tablo 2). 
Tablo 1. Erkeklerin Tanımlayıcı Özellikleri

\begin{tabular}{|c|c|c|}
\hline \multirow{2}{*}{$\begin{array}{l}\text { Tanımlayıcı Özellikler } \\
\text { Yaş (ort) }\end{array}$} & \multicolumn{2}{|c|}{$\bar{x} \pm s s$} \\
\hline & \multicolumn{2}{|c|}{$63.26 \pm 7.13$} \\
\hline Medeni Durumu & $\mathrm{n}$ & $\%$ \\
\hline Evli & 110 & 91.7 \\
\hline Bekar & 10 & 8.3 \\
\hline \multicolumn{3}{|l|}{ Eğitim durumu } \\
\hline Okur-Yazar & 10 & 8.3 \\
\hline İlköğretim mezunu & 70 & 58.3 \\
\hline Lise ve Yüksekokul mezunu & 40 & 33.4 \\
\hline \multicolumn{3}{|l|}{ Çalışma durumu } \\
\hline Çalışıyor & 35 & 29.2 \\
\hline Emekli & 85 & 70.8 \\
\hline \multicolumn{3}{|l|}{ Yaşadığı yer } \\
\hline İl merkezi & 94 & 78.3 \\
\hline İlçe/Köy & 26 & 21.7 \\
\hline \multicolumn{3}{|l|}{ Prostat sorunu yaşama durumu } \\
\hline Yaşıyor & 46 & 38.3 \\
\hline Yaşamıyor & 74 & 61.7 \\
\hline \multicolumn{3}{|l|}{ Prostat muayenesi yaptırma durumu } \\
\hline Yaptıran & 47 & 39.2 \\
\hline Yaptırmayan & 73 & 60.8 \\
\hline \multicolumn{3}{|l|}{ PSA testi yaptırma durumu } \\
\hline Yaptiran & 36 & 30.0 \\
\hline Yaptırmayan & 84 & 70.0 \\
\hline \multicolumn{3}{|c|}{ Yakınlarında prostat kanser tanısı alma durumu } \\
\hline Alan & 34 & 28.3 \\
\hline Almayan & 86 & 71.7 \\
\hline \multicolumn{3}{|l|}{ Prostat kanseri bilgi alma durumu } \\
\hline Alan & 26 & 21.7 \\
\hline Almayan & 94 & 78.3 \\
\hline \multicolumn{3}{|l|}{ Bilgi alınan yer $(n=26)$} \\
\hline Arkadaş/Akraba & 6 & 23.0 \\
\hline Medya (İnternet/Tv/Gazate) & 12 & 46.2 \\
\hline Sağlık Personeli & 8 & 30.8 \\
\hline \multicolumn{3}{|l|}{ Prostat kanseri tarama yaptırma isteği } \\
\hline İsteyen & 88 & 73.3 \\
\hline İstemeyen & 32 & 26.7 \\
\hline \multicolumn{3}{|c|}{ Prostat kanseri tarama yaptırmama nedeni $(n=32)$} \\
\hline Gerek görmüyorum & 20 & 62.5 \\
\hline Yapılması gerektiğini bilmiyorum & 12 & 37.5 \\
\hline
\end{tabular}


Tablo 2. Erkeklerin Tanımlayıcı Özellikleri ve PKTBT Ortalamaları

\begin{tabular}{|c|c|c|c|}
\hline \multirow[t]{2}{*}{ Tanımlayıcı Özellikler } & \multicolumn{2}{|c|}{ Bilgi Testi Puan Ort. } & \multirow{2}{*}{$\begin{array}{c}\text { Test } \\
p\end{array}$} \\
\hline & $\mathbf{N}$ & $\bar{x} \pm s s$ & \\
\hline \multicolumn{4}{|l|}{ Eğitim durumu } \\
\hline Okur-Yazar & 10 & $4.50 \pm 1.64$ & \\
\hline İlköğretim mezunu* & 70 & $4.32 \pm 2.05$ & $0.00 *$ \\
\hline Lise ve Yüksekokul mezunu & 40 & $5.75 \pm 2.43$ & \\
\hline \multicolumn{4}{|l|}{ Yaşadığı yer } \\
\hline İl merkezi & 94 & $4.92 \pm 2.33$ & $0.54 * *$ \\
\hline İlçe/Köy & 19 & $4.57 \pm 1.86$ & \\
\hline \multicolumn{4}{|l|}{ Prostat sorunu yaşama durumu } \\
\hline Yaşıyor & 46 & $5.52 \pm 2.12$ & $0.00 * *$ \\
\hline Yaşamiyor & 74 & $4.37 \pm 2.21$ & \\
\hline \multicolumn{4}{|c|}{ Prostat muayenesi yaptırma durumu } \\
\hline Yaptıran & 47 & $5.55 \pm 2.11$ & \\
\hline Yaptirmayan & 73 & $4.34 \pm 2.21$ & $0.00 * *$ \\
\hline \multicolumn{4}{|c|}{ Yakınlarında prostat kanseri tanısı alma durumu } \\
\hline Alan & 34 & 5.55 & \\
\hline Almayan & 86 & 4.52 & $0.02 * *$ \\
\hline \multicolumn{4}{|c|}{ Prostat kanseri tarama yaptırma isteği } \\
\hline İsteyen & 88 & $5.25 \pm 2.26$ & \\
\hline İstemeyen & 32 & $3.62 \pm 1.73$ & $0.00 * *$ \\
\hline
\end{tabular}

*One way Anova testi yapılmıştır. ** Independent t testi yapıllmıştır.

Tablo 3. Erkeklerin Bilgi Durumlarına Göre PKTBT Ortalamaları

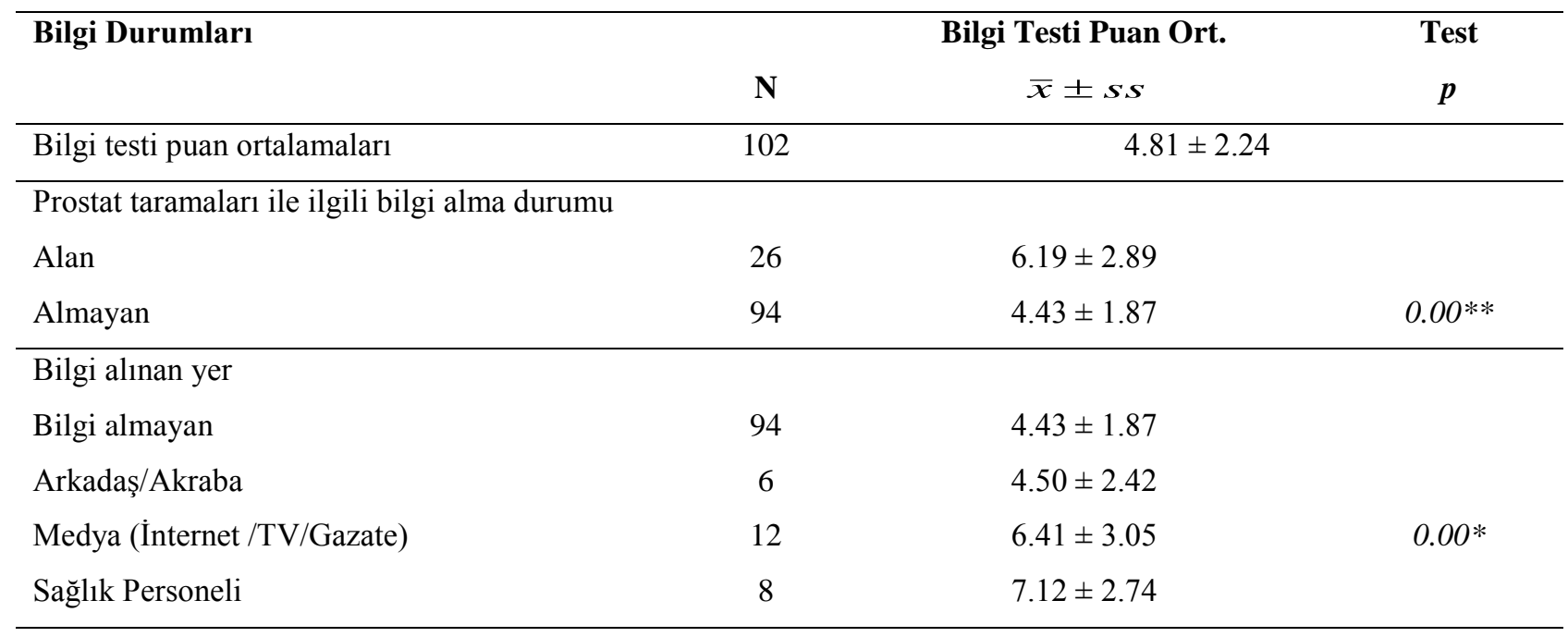

*One way Anova testi yapılmıştır. ** Independent t testi yapılmıştır. 
Araştırma kapsamında erkeklerin daha önce prostat kanseri hakkında bilgi alanların prostat kanseri bilgi test puan ortalaması $6.19 \pm 2.89$, bilgi almayanların bilgi test puan ortalaması $4.43 \pm 1.87$ bulunmuş ve aradaki farkın istatistiksel olarak anlamlı olduğu tespit edilmiştir $(p<0.05)$. Erkeklerin bilgi aldıkları yerlere bakıldığında, en yüksek puanı sağlık personelinden bilgi alanların oluşturduğu ve gruplar arasındaki farkın anlamlı olduğu bulunmuştur $(\mathrm{p}<0.05)$. Gruplar arası farkın tespit etmek için yapılan ileri istatistiki değerlendirmede anlamlılığın bilgi almayanlar ile sağlık personelinden alanlar arasındaki farktan kaynaklandığı saptanmıştır (Tablo 3).

\section{TARTIŞMA}

Erkeklerin prostat kanseri taramalarına katılmalarını birçok faktör etkilemektedir. Bu faktörlerin içerisinde "bilgi eksikliği" taramalara katılımı etkileyen önemli bir faktördür. Uluslararası birçok çalışmada prostat kanseri taramalarına yönelik bilgi düzeyinin önemi incelenmektedir $(16,17,26)$. Bu çalışmada erkeklerin prostat kanseri taramalarına ilişkin bilgi düzeylerinin belirlenmesi amaçlanmıştır.

Çalışmadaki erkeklerin bilgi düzeylerine bakıldığında “düşük düzeyde bilgili” oldukları görülmektedir. Amerika ve İrlanda'da yapılan çalışmalarda erkeklerin prostat kanseri hakkında yeterli farkındalıklarının olduğu ve yüksek düzeyde bilgiye sahip oldukları bildirilmiştir (27,28). Çalışmamız literatürden farklılık göstermektedir. Türkiye için yeterli çalışma bulunmamasına rağmen, bu farklılığın ülkeler arasındaki kültürel yapıdan, ülke politikasındaki bilgilendirme ve farkındalık çalışmalarının yeterliliği ve etkinliğinden kaynaklanabileceğini düşündürmektedir.

Çalışmadaki erkeklerin sadece \%21.7'sinin prostat kanseri ve taramalarına ilişkin daha önce bilgi aldığı ve bilgi almayanlarla anlamlılık oluşturacak düzeyde fark oluşturdukları belirlenmiştir. Ayrıca sağlık personelinden bilgi alanların bilgi puanları en yüksek bulunmuş, gruplar arasındaki fark anlamlılık göstermiştir. Literatür incelendiğinde birçok çalışmada, prostat kanserine yönelik yüksek bilgi düzeyine sahip olmanın taramalara katılımı olumlu yönde etkilediği görülmektedir $(17,26,29)$.

Ford ve arkadaşları prostat kanserine yönelik bilgi eksikliğinin taramalara katılımda önemli bir engel olduğunu bildirmiştir (17). Livingston ve arkadaşları, erkeklerin bilgi düzeylerinin taramalara katılımı 1.5 kat arttırdığını saptamışlardır (29). Çalışmamız literatürle benzerlik göstermektedir. Taramalara ilişkin sağlık personeli tarafindan amaca uygun verilen eğitimin daha etkin olması diğer bilgilendirmeden daha fazla yarar algısı ve farkındalık oluşturmasından kaynaklanabilir. $\mathrm{Bu}$ durum sağlık personellerinin yönlendirmeleriyle erkeklerin taramalara katılımını artırabileceğini düşündürmektedir.

Erkeklerin daha önceki deneyimleri ile bilgi puan ortalamaları arasında, daha önce prostat sorunu yaşayanlarda, daha önce prostat muayenesi yaptıranlarda ve yakınlarında prostat kanseri tanısı olanlarda bilgi testi puan ortalamaları daha yüksek bulunmuştur. $\mathrm{Bu}$ durum deneyimlerin ve risk altında hissetmenin bilgilendirme kadar etkin olduğu ve bireylerin sağlıklı yaşam biçimi davranışlarına eğilimlerini arttırmasıyla açıklanabilir. Yapılan çalışmalarda da bireylerin risk altında olduğunu düşünmesinin taramalara katılımda etkili olduğu bildirilmiştir (30,31). Nitekim bu çalışmada erkeklerin \%73.3'ünün bundan sonra tarama yaptırma isteğinde olduğunu ifade etmesi de yapılan çalışmaları destekleyen bir veridir.

Eğitim durumu taramalara katılımı arttıran değişkenlerden biridir. Eğitim düzeyi arttıkça bireylerin duyarlılıkları da artmaktadır (32). Yapılan bir çalışmada eğitim arttıkça güven ve yarar algısının arttığı bildirilmiştir (33). Bidouei ve arkadaşlarının İran'da 1060 kişide yaptığı çalışmada eğitim düzeyinin yüksek olmasının taramalara ilişkin algıyı olumlu etkilediği saptanmıştır (34). Bu çalışmada da eğitim düzeyi arttıkça bilgi testi puan ortalamalarının arttığı belirlenmiştir. Bu bakımdan incelendiğinde çalışmamız yine literatürle benzerlik göstermektedir. 
$\mathrm{Bu}$ araştırmanın sonucunda riskli grupta yer alan erkeklerin prostat kanseri ve erken tanılama için taramaların önemi hakkında bilgi sahibi olmadığı, çok az sayıda bilgi alanların ise bilgi almayanlara göre farkındalıklarının ve bilgilerinin anlamlı düzeyde etkilendiği görülmüştür. Erkeklerin deneyimleri ile bilgi düzeylerinin arttığı, ancak yine de normalin altında olduğu tespit edilmiştir. Bunun için özellikle riskli gruplarda daha sık görülen kanserlere ilişkin farkındalıkları arttırmak için ülkemizde eğitimlerin verilmesi, kamu spotlarının oluşturulması, medyanın etkin olarak kullanılması ve taramalara katılımların arttırılması önerilebilir.

Teşekkür: Çalışmanın yapılmasında destek ve katılımları için Gonca Karakuş Açıkgöz'e ve Üroloji polikliniği çalışanlarına teşekkür ederiz.

Çalışmada herhangi bir çıkar çatışması bulunmamaktadır.

Çalışma için herhangi bir maddi destek ve fon kullanılmamıştır.

\section{KAYNAKLAR}

1. Akdemir N, Birol L. İç Hastalıkları ve Hemşirelik Bakım Kitabı. 2. Baskı. Ankara: Sistem Ofset. 2005. pp: 245-254.

2. Karadakovan A, Aslan F. Dahili ve Cerrahi Hastalıklarda Bakım Kitabı. 2. Baskı. Adana: Nobel kitabevi. 2011. 201-208.

3. Türkiye'de Kanser Kontrolü 2009. http://onkofar.com/vImages/pdfler/2009_Turkiyede kanserkontrolu.pdf. (Erişim tarihi: 08/03/2014)

4. GLOBOCAN 2012: Estimated Cancer Incidence, Mortality and Prevalence Worldwide in 2012. http://globocan.iarc.fr/Pages/fact_sheets_cancer.asp X. (Erişim tarihi: 09/03/2014)

5. Türkiye Cumhuriyeti Sağlık Bakanlığı: Sağlık İstatistikleri $\quad$ Yillığ1 2010. http://www.saglik.gov.tr/TR/dosya/172577/h/saglikistatistikleriyilligi2010.pdf. (Erişim tarihi: 08/03/2014)
6. Türkiye'de Prostat Kanseri İnsidansı: Epidemiyolojik bir Çalışma (PROSTATTURK). http://uroonkoloji9.naklenkongre.com/sunumlar/21 0800.pdf. (Erişim tarihi: 09/03/2014)

7. Jemal A, Murray T, Ward E, Samuels A, Tiwari RC, Ghafoor A et al. Cancer statistics, 2005. CA Cancer J Clin. 2005;55(1):10-30.

8. Prostat kanseri hastalar için bir kılavuz 2008. http://www.krebsgesellschaft-

nrw.de/d_service/b_runterladen/Prostata.pdf.

(Erişim tarihi: 08/03/2014)

9. Yüksel İ, Kaplan M. Prostat kanseri önlenebilir mi? Üroonkoloji Bülteni. 2011;2:17-21

10. Ekin RG, Zorlu F. Türkiye verilerine göre prostat kanseri taranmalı mi? Üroonkoloji Bülteni. 2013;12:71-75.

11. Türkeri L. Prostat kanserinde tarama ve kanser gelişimini önlemenin güncel durumu. Üroonkoloji Bülteni. 2009;1:14-15.

12. Schröder FH, Hugosson J, Roobol MJ, Tammela TLJ, Ciatto S, Nelen V et al. Screening and prostate-cancer mortality in a randomized european study. The new england journal of medicine. 2009;360:1320-1328.

13. Etzioni R, Gulati R, Cooperberg MR, Penson DM, Weiss NS, Thompson IM. Limitations of basing screening policies on screening trials. Med Care. 2013;51:295-300

14. Arkes HR, Gaissmaier W. Psychological research and the prostate- cancer screening controversy. Psychol Sci. 2012;23:547-553

15. Vu Le C, Quang Dao O, Khac Tran LN. Mass screening of prostate cancer in Vietnam: Current status and our opinions. Urologic Oncology: Seminars and Original Investigations. 2010;28:673676

16. Weinrich SP, Seger RE, Rao GS, Chan EC, Hamm RM, Godlet PA et al. A decision aid for teaching limitations of prostate cancer screening. J Natl Black Nurses Assoc. 2008;19:1-11. 
17. Ford, ME, Vernon SW, Havstad SL, Thomas SA, Davis SD. Factors influencing behavioral intention regarding prostate cancer screening among older African-American men. J Natl Med Assoc 2006;98:505-514.

18. Wray R J, McClure S, Vijaykumar S, Smith C, Ivy A, Jupka $\mathrm{K}$ et al. Changing the conversation about prostate cancer among African Americans: Results of formative research. Ethn Health. 2009;14:27-43.

19. Forrester-Anderson IT. Prostate cancer screening perceptions, knowledge and behaviors among African American men focus group findings. J Health Care Poor Underserved. 2005;16(4):22-30.

20. Sanchez MA, Bowen DJ, Hart A Jr, Spigner C. Factors influencing prostate cancer screening decisions among African American men. Ethn Dis. 2007;17:374-380.

21. Patel K, Kenerson D, Wang H, Brown B, Pinkerton $\mathrm{H}$, Burress $\mathrm{M}$ et al. Factors influencing prostate cancer screening in low-income African Americans in Tennessee. J Health Care Poor Underserved. 2010;21:114-126.

22. Jeanne M, Ferrante KE, Shaw GJ. Factors influencing men's decisions regarding prostate cancer screening: a qualitative study. J Comm Health. 2011;36:839-844

23. Agho AO, Lewis MA. Correlates of actual and perceived knowledge of prostate cancer among African Americans. Cancer Nurs. 2001;24:165-171.

24. Çapık C. Investigating the factors that affect the knowledge level regarding prostate cancer screenings. Turk J Urolog. 2012;38:185-189.

25. Weinrich SP, Seger R, Miller BL, Davis C, Kim S, Wheeler $\mathrm{C}$ et al. Knowledge of the limitations associated with prostate cancer screening among low-income men. Cancer Nurs. 2004;27:442-453.

26. Çapık C, Gözüm S. Prostat kanseri taramaları bilgi testinin Türk diline adaptasyonu. Turk J Geriatr. 2011;14:253-258.
27. Jemal A, Fedewa SA, Ma J, Siegel R, Lin CC, Brawley $\mathrm{O}$ et al. Prostate Cancer Incidence and PSA Testing Patterns in Relation to USPSTF Screening Recommendations. JAMA. 2015; 314(19):2054-2061.

28. Hevey D, Pertl M, Thomas K, Maher L, Chuinneagain SN, Craig A. The relationship between prostate cancer knowledge and beliefs and intentions to attend PSA screening among at-risk men. Patient Educ Couns. 2009;74(2):244-9.

29. Livingston P, Cohen P, Frydenberg M, Borland R, Reading D, Clarke V et al. Knowledge, attitudes and experience associated with testing for prostate cancer: a comparison between male doctors and men in the community. Intern Med Journal. 2002;32(5):215-223.

30. Bloom JR, Stewart SL, Oakley-Girvans I, Banks PJ, Chang S. Family history, perceived risk, and prostate cancer screening among African American men. Cancer Ep Bio Prev. 2006; 15(11):2167-73.

31. Jacobs L. Health beliefs of rst-degree relatives of individuals with colorectal cancer and participation in health maintenance visits: a population-based survey. Cancer Nurs. 2002; 25(4):251-65.

32. Yılmaz M, Dereli F, Yelten G. Elli Yaş ve Üzerindeki Bireylerin Bazı Sosyodemografik Özellikleri, Sağlıklı Yasam Biçimi Davranışları ve Sağlık İnançlarının Kolon Kanserine İlişkin Tarama Davranışlarına Etkisi. Hemşirelikte Eğitim ve Araştırma Dergisi. 2016;13(3): 226-234.

33. Tastan S, Andsoy I I, Iyigun E. Evaluation of the knowledge, behavior and health beliefs of individuals over 50 regarding colorectal cancer screening. Asian Pac J Cancer Prev. 2013; 14(9):5157-63.

34. Bidouei F, Abdolhosseini S, Jafarzadeh N, Izanloo A, GhaffarzadehganK, Abdolhosseini A et al. Knowledge and perception toward colorectalcancer screening in east of Iran. Int J Health Policy Manag. 2014;3(1):11-15. 